\section{New Searchable Technical Gold Database from World Gold Council}

It is now possible to obtain a listing of the latest papers and patents on any area of gold science, technology or industrial application via the new Technical Database on the Council's website at www.gold.org/value/sci_indu/techdatabase.

Fields covered by the database include:

- ANALYSIS

- CATALYSIS

- CHEMISTRY

- DENTISTRY

- ELECTRONICS

- JEWELLERY

- MEDICINE

- NANOTECHNOLOGY

- ELECTRODEPOSITION/ELECTROPLATINC

- METALLURGY

- MATERIAL PROPERTIES

- RECYCLING/RECOVERY

- REFINING

- WASTE WATER TREATMENT
Using the database will allow you to:

- Obtain a list of recent (or historical) publication references on a particular topic

- Keep up to date with which publications are carrying papers in your chosen field

- Identify the exact reference for a particular paper

- Search for other references by a particular author or on a particular subject

The database is updated quarterly and, to date, contains over 700 records. Users can either search just the latest update or the full database. Each entry has been characterised by Keywords. The basis for a search can be either:-

- by these Keywords eg 'heterogeneous'

- by Document type eg 'patents'

- by a word from the publication Title

- or by Author Name.

Suggestions and comments on the usefulness of this database or opportunities to improve its effectiveness will be welcomed, email: richard.holliday@gold.org

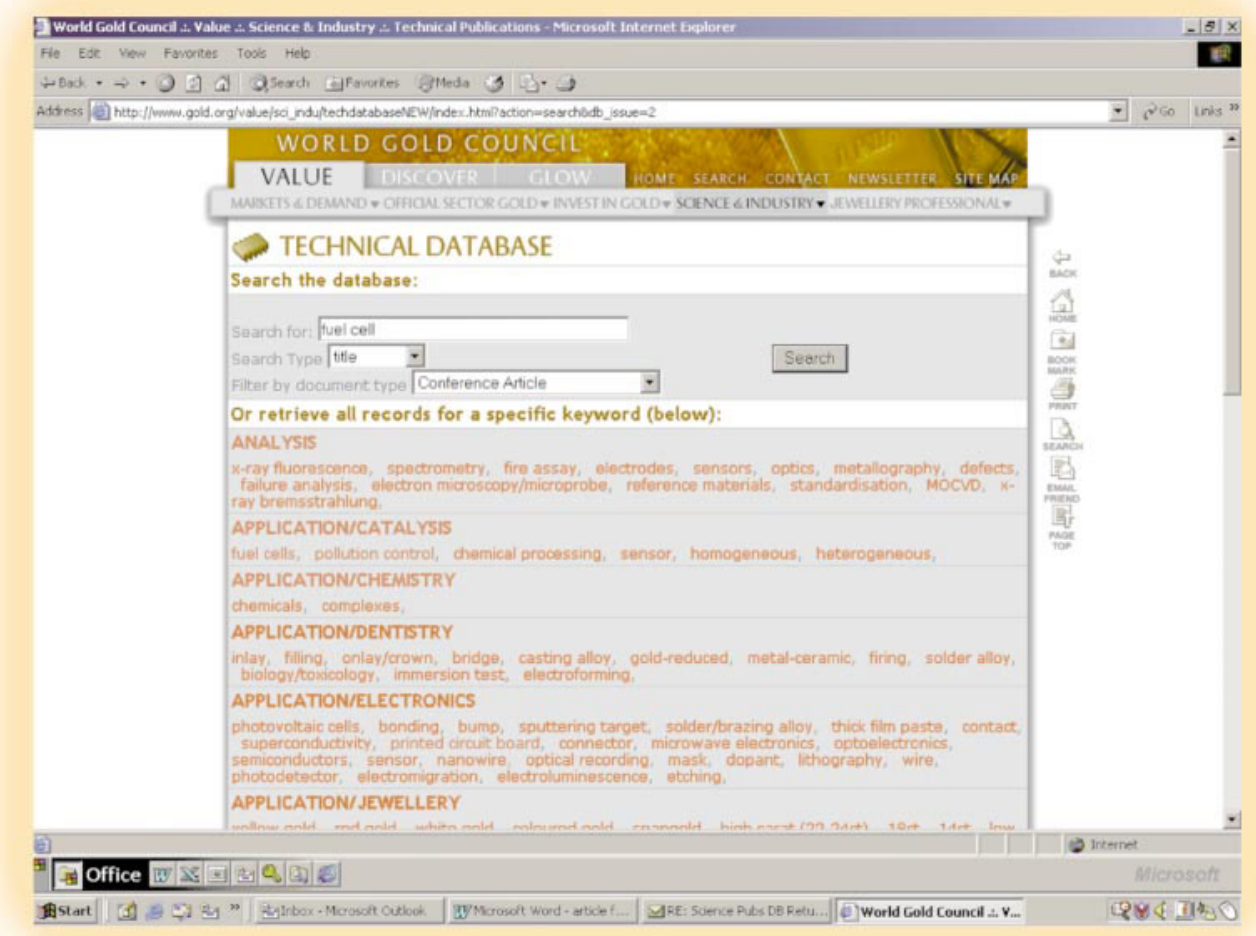

